\title{
Acercar a los aprendientes de FLE a los aspectos culturales del mundo francófono por medio de la plataforma Google Classroom.
}

\author{
Bringing FLE learners closer to the cultural aspects of the Francophone world through Google \\ Classroom.
}

\section{Azucena Ortiz-Martínez ${ }^{a}$}

\begin{abstract}
:
The objective of this article is to come up with a proposal to implement Google Classroom as a supplement to the "Actu culture" section of the Saison 1 textbook (Didier editorial, 2014). This proposal aims at raising learners' awareness on the cultural issues addressed in the textbook that is used to teach French in the courses that are offered at the Language Teaching Center of the University of Quintana Roo.

ICT is then seen as the means to scaffold learners to discover different cultural aspects of French-speaking countries, in order to boost their interest in the cultural diversity of the French language. At the same time, it seeks to provide the FLE teacher with additional resources that allows him to address the cultural issues proposed in Saison 1 with digital tools.

The choice of audiovisual materials and websites was made on the basis of the cultural topics pointed out in each unit, in the same way in which they are presented in the textbook because the purpose was to follow the curriculum of the course, trying to avoid the omission of contents of cultural nature to favor linguistic contents due to the lack of time in the language class.

The use of the online platform provides both teachers and learners with the opportunity to discover the Francophone world on the basis of activities that foster the understanding of other cultural realities, in flexible and dynamic ways. This also allows them to take advantage of the abundance of information that is available on the web and at the same time, the digital skills of teachers and learners are strengthened.
\end{abstract}

Keywords:

Culture, FLE, online platform, ICT

\section{Resumen:}

El objetivo de este artículo es el de presentar una propuesta para hacer uso de la plataforma Google Classroom como complemento de la sección Actu culture del libro de texto Saison 1 (editorial Didier, 2014). Con esta propuesta se busca sensibilizar, a los aprendientes, respecto a las temáticas culturales abordadas en el libro de texto que se utiliza en los cursos de francés del Centro de Enseñanza de Idiomas de la Universidad de Quintana Roo.

Por medio de las TIC se pretende hacer un puente para que los aprendientes descubran diferentes aspectos culturales de países francófonos, con el fin de despertar el interés hacia la diversidad cultural del idioma francés. A la par, se busca proveer al profesor de FLE con material adicional que le permita abordar los temas culturales propuestos en Saison 1 con herramientas digitales.

La elección de los materiales audiovisuales y sitios web se centró en las temáticas culturales indicadas en cada unidad, así como en el orden de aparición en el libro de texto con la intención de respetar el programa del curso y evitar así la omisión de contenidos de índole cultural, dando mayor importancia a los contenidos lingüísticos por falta de tiempo en la clase de lenguas.

El uso de la plataforma online ofrece un espacio de descubrimiento del mundo francófono a partir de actividades que fomenten el entendimiento de otras realidades culturales de forma flexible y dinámica. Además hace uso de la gran cantidad de información que existe en la web y fortalece las competencias digitales de docentes y aprendientes.

\footnotetext{
${ }^{a}$ Universidad de Quintana Roo, Centro de Enseñanza de Idiomas, https://orcid.org/0000-0001-8946-7958, Email: azucena@uqroo.edu.mx
} 


\section{Palabras Clave:}

Cultura, FLE, plataforma online, TIC

\section{INTRODUCTION}

El uso de las tecnologías de la información y la comunicación (TIC) se encuentra presente en todos los ámbitos y el educativo no queda exento. En la enseñanza de lenguas el uso de recursos didácticos en las aulas es común, como mencionan Soubrié y Dejean (2014), los libros de texto desde hace muchos años han venido acompañados de un complemento según las tecnologías de cada época cassettes, videos, CDROMs, ejercicios auto correctivos, hojas de trabajo, sitios web, plataformas online, entre otros. Las editoriales continuamente han provisto de materiales didácticos a los docentes de idiomas a lo largo del tiempo lo que ha permitido hacer una transición sin resistencia hacia el uso de TIC en las aulas, adoptando una actitud más bien positiva hacia la innovación didáctica y preparando en cierta medida a los docentes en el uso de herramientas digitales (Ramírez, Casillas y Contreras, 2014).

\section{Plataformas online}

La utilización de plataformas online como complemento de cursos presenciales o como herramienta de la educación a distancia se ha incrementado en todo el mundo. En México, la plataforma educativa Moodle ocupa el $5^{\circ}$ lugar en la preferencia del aprendizaje a distancia, además de ser "utilizada por más de mil 300 universidades de 160 países, con versiones en más de 75 idiomas disponibles" (UDG, 2015, p.1). En la Universidad de Quintana Roo (UQroo) los cursos educativos virtuales o híbridos también se imparten a través de esta plataforma.

Sin embargo, existen otras plataformas online como Google Classroom que permite una gestión sencilla de las clases, los profesores pueden crear tareas, compartir material y recursos de la red. Además la comunicación es en tiempo real y se puede acceder desde cualquier dispositivo, en cualquier lugar, a más de contar con una aplicación móvil y ser de acceso gratuito.

En este contexto, algunas instituciones educativas dan libertad de cátedra a los docentes para implementar en sus cursos, el uso de plataformas educativas virtuales alternas como complemento de las clases presenciales; no así, en los cursos previamente diseñados a distancia en la institución. La gestión del aprendizaje puede abordarse desde distintas vertientes y hacer uso de las tecnologías de la información para extender el campo de acción de los profesores y las instituciones educativas, como puntualiza la UNESCO (2015): "Es indispensable aprovechar las tecnologías de la información y la comunicación (TIC) para fortalecer los sistemas educativos, difundir los conocimientos, brindar acceso a la información, promover un aprendizaje de calidad y efectivo, y prestar servicios de forma más eficaz" (párr. 2).

\section{Cursos de francés lengua extranjera (FLE)}

La Universidad de Quintana Roo, cuenta con cuatro campus: Chetumal, Cozumel, Playa del Carmen y Cancún. En el campus Chetumal, el Centro de Enseñanza de Idiomas (CEI), tiene la encomienda de organizar e impartir las clases presenciales de idiomas para todos los Programas académicos de la universidad, así como para el público externo que desee cursarlos.

Actualmente, en el CEI de la UQroo, se imparten cursos de inglés, francés, italiano, portugués, alemán, maya y español para extranjeros. Los cursos de lenguas buscan desarrollar la competencia lingüística y cultural de los estudiantes de las diferentes carreras universitarias. Los cursos de idiomas se encuentran conformados por seis niveles, para los idiomas diferentes al inglés, cada nivel consta de 80 horas, las cuales se distribuyen en cinco horas semanales o en cursos sabatinos.

En cuanto al idioma inglés, por su obligatoriedad en toda la universidad, tiene el estatus de Asignatura General (AG) y otorga seis créditos. En el caso de los demás idiomas ofertados en el CEI, éstos forman parte de la formación integral de los estudiantes, como materia de apoyo y conceden dos créditos únicamente.

Por otro lado, en el CEI de la Universidad de Quintana Roo, los cursos de idiomas tienen como punto de apoyo un libro de texto; en el caso concreto de la enseñanza del francés se trabaja con el libro Saison 1, de la editorial Didier (Cocton, 2015).

\section{Libro de texto Saison 1.}

El libro de texto Saison 1 se publicó en el 2015 y se enfoca en un público adulto y en adolecentes mayores. Se conforma de nueve unidades con las que se alcanza el nivel A1, de la unidad cero a la seis, y principios del A2, de la unidad siete a la nueve.

Las unidades de aprendizaje están distribuidas en tres módulos, conformados cada uno por tres unidades de aprendizaje. Cada unidad se encuentra estructurada por etapas como se muestra en la figura 1.

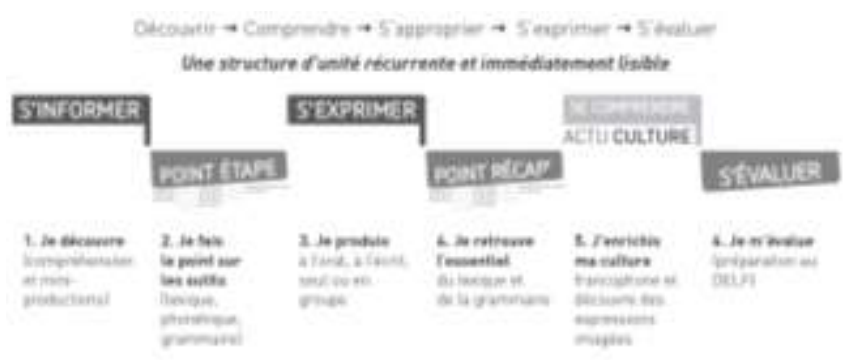

Figura 1. Estructura las unidades en Saison 1 (Cocton, 2015).

La guía pedagógica de Saison 1 (Cocton y Pommier, 2015) indican que el libro de texto "se apoya en los principios pedagógicos descritos en el MCERL y en la línea de enfoques comunicativo y orientado a la acción” (p.3) (traducción libre).

\section{Actu culture}


Durante el desarrollo de cada unidad de aprendizaje, se abordan el componente lingüístico, el sociolingüístico y el pragmático. Asimismo, cada unidad tiene una sección llamada Actu culture, la cual encamina a descubrir y a poner en relieve elementos culturales de distintos países francófonos, con la finalidad de despertar el interés de los aprendientes de francés hacia la diversidad cultural que rodea el aprendizaje del idioma.

La guía pedagógica de Saison 1 (2015, p. 8), destaca la flexibilidad para abordar los contenidos culturales durante el curso, el docente podría dedicarles una secuencia completa o alternar a lo largo de cada unidad para enfocarse en un elemento en específico, ya que los aspectos culturales se presentan de forma transversal.

Las temáticas culturales abordadas en la sección Actu culture son nueve y se muestran en el mismo orden de aparición en cada unidad:

1. La France

2. Tour de France et des régions

3. Les fêtes et traditions

4. La langue française en partage

5. La gastronomie française, une question de goût

6. La Belgique, Carrefour de l'Europe

7. L'invention, un destin commun

8. Découvrir, apprendre, réussir

9. L'art au coin de la rue

A manera de ilustración del contenido de la sección Actu culture, en la unidad seis, la temática cultural se centra en Bélgica. Por un lado se presentan algunos datos puntuales sobre Bélgica, también se enlistan las instituciones europeas con sede en ese país, así como los museos más representativos. Por otro lado, se da una pequeña lista de palabras en francés con variación lingüística y un pequeño apartado hace alusión a los cambios en la pronunciación de ciertos sonidos. Igualmente se hace mención de la ciudad de Brujas y se destaca la fama del chocolate como especialidad gastronómica. En este apartado también se hace alusión a una expresión idiomática belga y se proponen dos mini tests de comprensión de la información proporcionada. Ver figura 2.

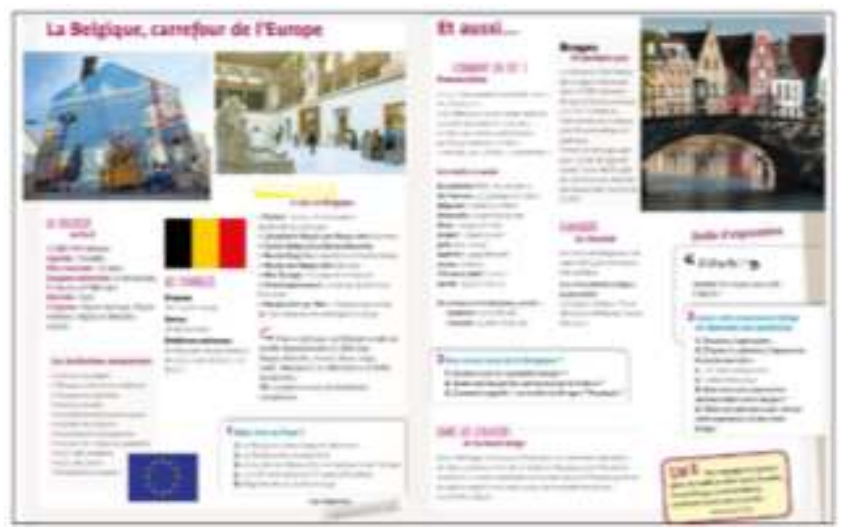

Figura 2. Sección Actu culture, unidad 6, Saison 1. (Cocton 2015).

Hasta este punto hemos visto que el libro de texto Saison 1, a través de la sección Actu culture aporta un esbozo de elementos culturales en cada unidad, con el objetivo de sensibilizar a los aprendientes a las diferencias culturales francófonas y así promover comprensión, tolerancia y respeto hacia lo que es desconocido. Sin embargo, esta finalidad, en algunos contextos áulicos no se consigue porque en ocasiones, algunos docentes conceden un lugar preferencial a los contenidos lingüísticos en detrimento de los contenidos de índole cultural en la enseñanza de idiomas.

Algunas razones que presuponen esta tendencia por parte de los profesores de lengua podrían ser la falta de tiempo, el centrarse en dar cumplimiento al contenido lingüístico del curso o incluso desinterés o falta de conocimiento para abordar las temáticas culturales.

Y es, precisamente, en la búsqueda de facilitar el trabajo de los docentes de francés que surge la propuesta de incorporar las TIC para promover el entendimiento de otras realidades culturales de forma atractiva y dinámica.

\section{Propuesta}

Se propone la creación de un espacio virtual de descubrimiento del mundo francófono, en donde se provea al profesor de FLE de material extra para abordar las diferentes temáticas culturales francófonas propuestas en Saison 1. Para ello se usará la plataforma Google Classroom. Al mismo tiempo se busca contribuir al desarrollo de las competencias digitales e interculturales de estudiantes y profesores, así como a promover el trabajo colaborativo en vistas a una mejora en la calidad educativa mediante el uso de las TIC.

\section{Google Classroom}

La elección de la plataforma Google Classroom obedece a sus características, entre las que destacan la facilidad de acceso y uso. Esta plataforma educativa es gratuita, sólo requiere de una cuenta Gmail, además puede usarse con cualquier dispositivo y en cualquier lugar; siempre y cuando se cuente con una conexión a internet y también cuenta con una Aplicación móvil para que los aprendientes puedan acceder a los recursos.

Las diversas ventajas que ofrece a los profesores el aula virtual de Google Classroom se ilustran en la figura 3.

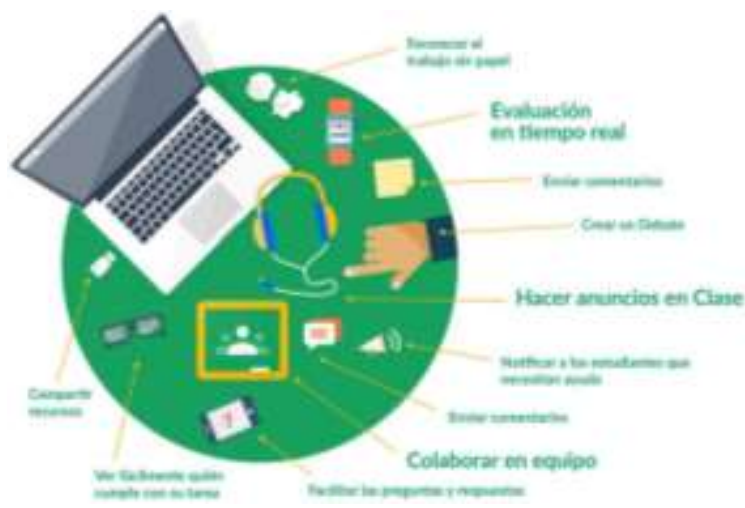

Figura 3. Ventajas de un aula virtual con google Classroom http://elearningmasters.galileo.edu/2017/03/20/aula-virtualcon-google-classroom/

Otras de las razones para optar por esta plataforma, fue contar con la experiencia previa de haberla utilizado en cursos anteriores. Es por ello, que se decidió alojar en Google 
Classroom la propuesta de material complementario sobre temas culturales propuestos en la sección Actu culture, en el libro Saison 1.

\section{Desarrollo de la propuesta de trabajo de Actu culture}

Para la realización de la propuesta de trabajo de Actu culture en la plataforma Google Classroom, en primer lugar se enlistaron las temáticas culturales presentadas en cada una de las unidades de Saison 1; en segundo lugar se hizo una búsqueda en internet y en carpetas personales de materiales relacionados con el tema abordado; se buscó que fueran atractivos, diversos, fiables, dinámicos y acordes al nivel de la lengua conforme al avance por unidad. En tercer lugar se seleccionaron las actividades más pertinentes al contexto de enseñanza, por unidad de aprendizaje.

El paso siguiente fue la creación del aula virtual, en la página principal de Google Classroom, se creó el aula para Actu culture, se optó por poner la foto del libro de texto Saison 1 (Cocton, 2015), así como una imagen del espacio francófono como portada de la clase.

Al momento de crear la clase, en automático se le asigna un código que fungirá como clave de acceso al aula virtual, como se ilustra en la figura 4; los alumnos también podrán acceder a ella enviándoles el enlace vía correo electrónico.

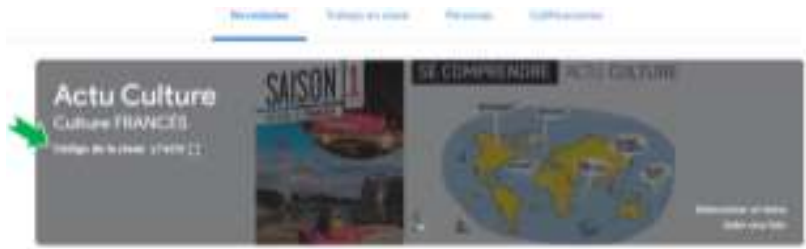

Figura 4. Página principal de la plataforma Actu culture en Google Classroom

\section{Las actividades}

Las actividades del aula Actu culture en Google Classroom fueron organizadas de la siguiente manera, una vez creada la clase, se procedió a organizar las actividades por unidad; para ello en la pestaña "trabajo en clase" se seleccionó el tipo de actividad que se quería crear, se le colocó un título, se redactaron las instrucciones para realizar la(s) actividad(es) y en algunos casos se agregó un vínculo y en otros un video o un archivo adjunto. Ver figura 5.

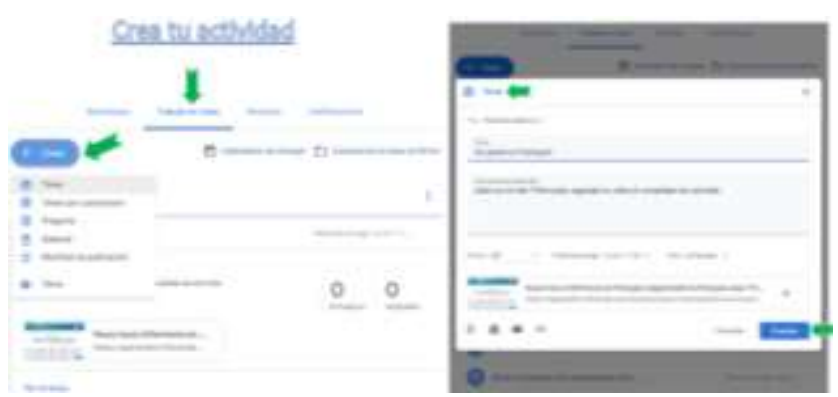

Figura 5. Creación de la actividad

Previo a la publicación de la actividad, se le fue asignado un tema, para efectos de una mejor organización del aula, los temas contenían el nombre de la temática cultural y número de la unidad respetando la secuencia establecida en el libro de trabajo Saison 1.
Posteriormente, se otorgó un puntaje a la tarea y aunque existe la posibilidad de establecer la fecha de entrega, no se le impuso una fecha límite. Por último se guardó la tarea y quedó asignada. De esa misma forma, se fueron estableciendo todas las actividades en cada una de las unidades. En la figura 6 se presenta un ejemplo de tareas asignadas en Google Classroom.

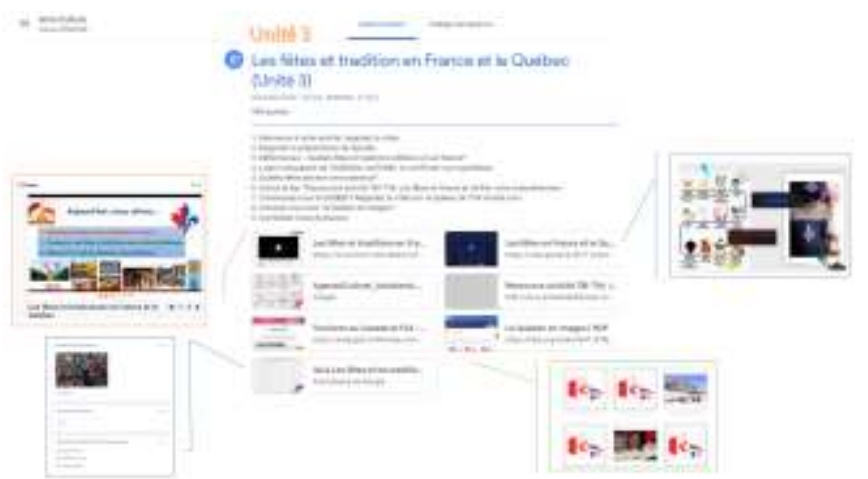

Figura 6. Ejemplo de tareas asignadas.

Complementario a las actividades, se diseñó una ficha de autoevaluación para aplicar al término de cada unidad, independientemente de la temática cultural, con la finalidad de hacer reflexionar a los estudiantes sobre las similitudes y/o diferencias encontradas; así como despertar su curiosidad y motivarlos a querer saber más, en vías de generar un cambio de paradigma.

La autoevaluación se encontrará disponible en la plataforma y se prevee también contar con un formato online para hacerla más versátil. En la figura 7 se puede ver un ejemplo de la ficha de autoevaluación.

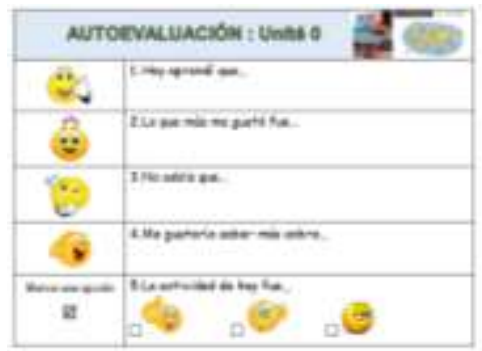

Figura 7. Ficha de Autoevaluación

Otro punto adicional a la propuesta fue añadir una temática cultural a la unidad cero, justamente como primer contacto con la lengua francesa, reconociendo el espacio francófono y sensibilizando sobre la presencia del idioma francés, más allá de Francia, que para la gran mayoría de los estudiantes mexicanos es un aspecto desconocido. Ver la figura 8. 


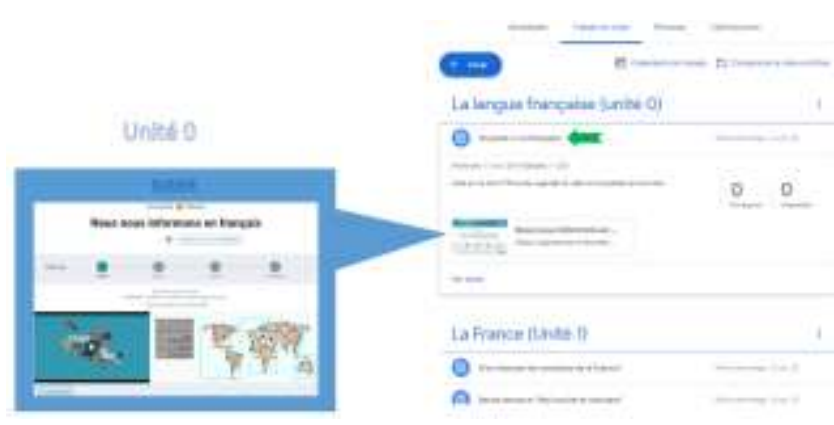

Figura 8. Anexo de la unidad 0

Igualmente, se proyecta invitar a los profesores de FLE del CEI de la UQroo a participar en esta aula virtual para trabajar de manera colaborativa, asignándoles un rol de administradores. En el marco de un trabajo colaborativo, los docentes contribuirían a la mejora del espacio de aprendizaje en línea, analizando el material existente, proponiendo modificaciones a lo existente y/o diseñando actividades complementarias, a la par de dar acompañamiento a los alumnos, que serán integrados a la plataforma al inicio de cada periodo escolar.

La plataforma Google Classroom permite integrar profesores como se visualiza en la figura 9.

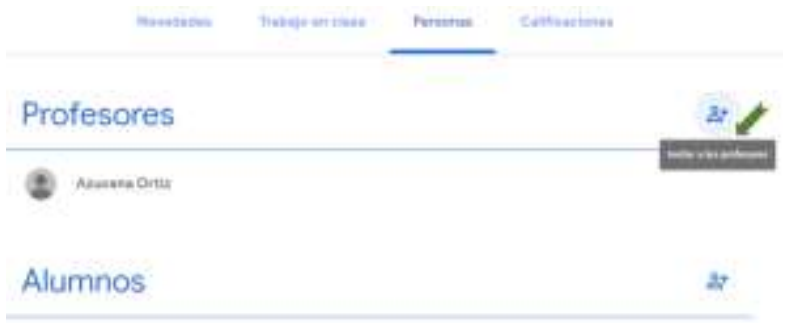

Figura 9. Invitación a profesores.

\section{Conclusiones}

La propuesta de complementar el curso de francés para promover el descubrimiento del mundo francófono usando una plataforma educativa como Google Classroom u otra, quizás no sea nueva para algunos maestros, como lo señalan Ramírez et al. (2014): "La cultura académica de los profesores de Idiomas, por tradición incluye el uso de la tecnología como herramienta docente" (p.125). Aunado a eso, si se proveen materiales digitales de índole cultural para hacerlos más accesibles, interesante y dinámicos, no sólo facilitaría la tarea docente, sino todo el proceso de enseñanza-aprendizaje.

La selección de materiales sobre temáticas culturales, si bien, siguen un orden establecido por el libro de texto de Saison 1, no deja de ofrecer un esbozo de "la realidad del mundo francófono" (Cocton y Pommier, p.4), aplicable en cualquier contexto de enseñanza del idioma francés y podría ser un detonante en el desarrollo de la competencia intercultural de los estudiantes.

Por otro lado, a los docentes del área de francés del CEI de la UQRoo, estos recursos les apoyarían en sus clases presenciales o a distancia. Sin duda, la propuesta de Actu culture en la plataforma Google Classroom ofrece una alternativa a los profesores en el diseño de actividades en línea, de forma inmediata. Es un ahorro de tiempo para la búsqueda o creación de materiales digitales; así mismo, al compartir recursos en línea se suprimirían los materiales impresos, además de dar continuidad al programa del curso sin perder la progresión, e igual de importante es el hecho de que se fomentaría y enriquecería el trabajo colaborativo entre los profesores del área.

En contraste con los estudiantes, ellos tendrían acceso a un espacio de reflexión, de acercamiento a realidades culturales de países francófonos, en aras de abonar a la comprensión mutua y poniendo distancia a los estereotipos.

Diversos estudios señalan el uso de tecnología como un detonante motivacional entre los estudiantes, generando una participación más activa. Por lo tanto, una plataforma accesible, gratuita y amigable como Google Classroom, se convierte en una buena opción para gestionar y organizar clases virtuales, facilitando el proceso de enseñanzaaprendizaje, la participación y autonomía de los aprendientes, la comunicación y la interacción en línea, así como el trabajo colaborativo.

A título personal, las TIC ponen al alcance de todos un sinfín de recursos para gestionar los aprendizajes, sin embargo, sólo los profesores podrán decidir su inclusión dentro de su aula presencial o virtual.

\section{REFERENCIAS}

1] Cocton, M.N., Élodie H., Catherine, H., Émilie, K., Dorothée, K. \& Delphine, R. (2015). Méthode de français Saison 1. Paris : Les Éditions Didier.

[2] Cocton, M.N. \& Pommier, É., (2015). Guide pédagogique Saison 1. Paris : Les Éditions Didier. Recuperado de https://www.editionsdidier.com/fr/sous-collection/saison-1-a1a2

[3] E-learning Masters. (2017). Cómo gestionar el aula virtual con Google Classroom [infografía]. http://elearningmasters.galileo.edu/2017/03/20/aula-virtual-con-googleclassroom/

[4] Ramírez Martinell, A., Casillas, M.A. \& Contreras, C.C., (2014). La incorporación de las TIC a la enseñanza universitaria de los idiomas. Revista Debate Universitario. vol.3, no. 5. pp. 123- 138, República Argentina. Recuperado de: http://portalreviscien.uai.edu.ar/ojs/index.php/debateuniversitario/article/view/20

[5] Thierry Soubrié \& Charlotte Dejean-Thircuir (febrero 2014). L'introduction du numérique dans les manuels de FLE : un moyen de repenser les finalités de l'éducation et les approches pédagogiques? Les manuels scolaires et le numérique - Journée Pierre Guibert, Université Montpellier 2 et 3 et IUFM de Montpellier 2, Montpellier, France. Recuperdo de http://hal.univ-grenoble-alpes.fr/hal-01162397/document

[6] Ulloa, J.L. (14 de julio de 2015). México, quinto país con más registro de uso de la plataforma virtual Moodle. Universidad de Guadalajara. Recuperado de:_http://www.udg.mx/es/noticia/mexico-quinto-pais-conmas-registro-de-uso-de-la-plataforma-virtual-moodle

[7] UNESCO (2015). Mejores prácticas de aprendizaje móvil. Recuperado de https://es.unesco.org/themes/tic-educacion/aprendizaje-movil/fazheng 